\title{
Elemental Composition of the Medicinal Plants Hypericum perforatum, Urtica dioica and Matricaria chamomilla Grown in Ukraine: A Comparative Study
}

\author{
Tetiana Derkach ${ }^{1 *}$, Volodymyr Khomenko²
}

\section{Tetiana Derkach ${ }^{1 *}$, Volodymyr Khomenko²}

\section{Department of Industrial Pharmacy, Kyiv National University of Technologies and Design, Nemyrovicha-Danchenko Str. 2, Kyiv, 01011, UKRAINE. 'Department of Electrochemical Energetics and Chemistry, Kyiv National University of Technologies and Design, Nemyrovicha-Danchenko Str. 2, Kyiv, 01011, UKRAINE. \\ Correspondence \\ Dr. Tetiana Derkach}

Department of Industrial Pharmacy, Kyiv National University of Technologies and Design, Nemirovicha-Danchenko Str 2, Kyiv, 01011 UKRAINE.

Phone no: +380-97-2691464

E-mail: derkach.tm@knutd.edu.ua

History

- Submission Date: 09-11-2017

- Review completed: 22-12-2017;

- Accepted Date: 16-02-2018

DOI : 10.5530/pj.2018.3.80

Article Available online

http://www.phcogj.com/v10/i3

\section{Copyright}

(c) 2018 Phcog.Net. This is an openaccess article distributed under the terms of the Creative Commons Attribution 4.0 International license.

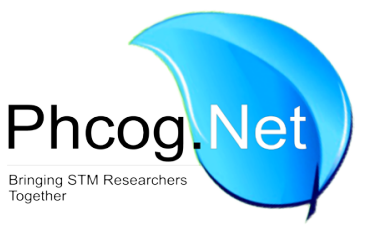

\begin{abstract}
Objective: To determine concentrations of essential microelements $\mathrm{Fe}, \mathrm{Cu}, \mathrm{Mn}$ and $\mathrm{Zn}$, as well as toxic metals $\mathrm{Pb}, \mathrm{Cd}, \mathrm{Cr}$ and $\mathrm{Co}$, in three herbal remedies and compare the experimental data obtained with available literature data. Materials and Methods: Elemental compositions of three herbal remedies, Chamomile flowers, Urtica folia (nettle) and Hyperichi herba (St John's wort), grown and produced in Ukraine, were studied by flame atomic absorption spectroscopy. Results: The Fe concentration decreases, as well as the Zn and Mn concentrations, increase in going from nettle through chamomile to St John's wort. The Cu content is virtually independent of the plant type. Statistically significant negative correlations between the element concentrations were found in Fe-Mn and Fe-Zn pairs. The studied samples of St John's wort are more contaminated with $\mathrm{Cd}$ than other plants, while the highest $\mathrm{Pb}$ content is observed in some samples of nettle. Conclusion: The measured levels of both $\mathrm{Pb}$ and $\mathrm{Cd}$ still secure against overuse of toxic metals with herbal remedies.
\end{abstract}

Key words: Medicinal plants, Atomic absorption spectroscopy, Elemental composition, $\mathrm{Pb}$, Cd contamination.

\section{INTRODUCTION}

Last decades the use of medicinal plants for the prevention and treatment of various sicknesses has increased remarkably in line with the global trend of people returning to natural therapies. Herbal medicines are often considered to be less toxic compared to chemical substances and with reduced adverse effects on the human organism. ${ }^{1}$ However, it is not entirely correct to consider them a priori safe products.,3

Conventional medicines consist of a limited number of purified compounds. Their safe doses are wellestablished. Ingress of any organic or elemental impurities is controlled on all stages of the pharmaceutical production. On the contrary, medicinal plants may contain a mixture of chemical compounds and elements. In the quality assessment of medicinal plants, the primary focus lies, generally, on active pharmaceutical ingredients. But herbs always contain a broad spectrum of both metals and metalloids. Their concentrations vary in a wide range depending on various botanical, environmental and agricultural factors. ${ }^{4,5,6}$

Some heavy metals such as $\mathrm{Pb}, \mathrm{Cd}$, and $\mathrm{Hg}$ are natural constituents of the environment or generated by industrial processes. Medicinal plants, which grow in nature, can accumulate heavy metals. As heavy metals threaten human and animal health, their content in plants used for consumption or medicinal purposes is limited. However, many studies report abnormally high levels of certain toxic elements compared to their safe/tolerable exposures in medicinal plants. ${ }^{6,7,8}$ Some other microelements participate in biochemical processes and are known as essential elements. ${ }^{9}$ Many essential elements may also be toxic to human health depending on dose..$^{10}$ However, their content is not controlled and restricted in herbal medicines. Summing up, the elemental composition of commercial medicinal herbs may vary in a wide concentration range, including both toxic and essential trace elements. The lack of regulation on the manufacturing of herbal medicines allows potentially harmful quantities of these elements to penetrate the products. Therefore, determining elemental compositions of medicinal plants is crucial. Three herbs widely distributed in Ukraine and many other countries are studied in the given work. They are nettle, chamomile, and St John's wort. The paper goal is to study elemental composition of the plants mentioned above, including the study of possible correlations between element concentrations and comparative analysis of compositional differences between plants. 


\section{MATERIALS AND METHODS}

The specimens of herbal remedies, Herba Hyperici (commonly known as St John's wort), Flores Chamomilla (chamomile) and Folia Urtica (nettle), were bought at local pharmacies in Kiev, Ukraine. Before analysis, the samples were ground in a high-speed rotor mill to obtain a homogeneous sample and stored in polyethylene containers.

All chemicals purchased from commercial sources were of analytical grade. Accurately weighed 2 g-in-weight plant samples were placed into a Teflon reaction crucible and treated with $10 \mathrm{ml}$ of $30 \% \mathrm{H}_{2} \mathrm{O}_{2}$ / concentrated $65 \% \mathrm{HNO}_{3}(1: 4, \mathrm{v} / \mathrm{v})$. Decomposition of the samples was carried out in a closed-vessel microwave digestion system. The digestion program consisted of three stages and was as follows: $80 \%$ power for $15 \mathrm{~min}, 100 \%$ for $5 \mathrm{~min}$ and $80 \%$ for $20 \mathrm{~min}$. After cooling, the clear digested solutions were transferred quantitatively into clean volumetric flasks and made up to $50 \mathrm{ml}$ with twice distilled water. Blank experiments were carried out in the same way. Three independent digestions were performed for each plant specimen. The digests were used to determine concentrations of $\mathrm{Cu}, \mathrm{Zn}, \mathrm{Fe}, \mathrm{Mn}, \mathrm{Pb}, \mathrm{Cd}, \mathrm{Co}$ and $\mathrm{Cr}$ by flame atomic absorption spectroscopy (FAAS). A double-beam Solaar S4 AA Spectrometer (Thermo Electron Co., USA) was used, applying standard conditions in air/acetylene flame and $\mathrm{D}_{2}$ correction. The quantitative determinations were carried out by external calibration with the use of certified reference materials produced by Bogatsky Physics-Chemistry Institute (Odessa, Ukraine). The working range for each element was within a linear range of the method. Calibration intervals were adjusted according to the expected concentrations of elements. Measurement of each sample was repeated three times, and the mean value was calculated. Both own experimental results and available literature data for individual plants under study were analysed by statistical methods using IBM SPSS 20 software. The results were expressed either as the means $\left(C_{m}(\exp )\right)$ with standard errors of the mean (SEM) for data with a normal distribution or medians $\left(C_{\text {med }}\right)$ and quartiles for asymmetric distributions. All data were tested for normal distribution with the Shapiro-Wilks model and variance homogeneity with the Levene's test. Any correlations between microelement contents were examined with the use of Pearson correlation coefficients ( $r i j)$.

One-way analysis of variance (ANOVA) was used to analyse possible differences among the mean concentrations. The significance level $\alpha$ was set at or below $5 \%(\alpha \leq 0.05)$. If the significant differences were found to exist among the means, then post hoc pairwise multiple comparisons were applied to determine which means differ. Depending on the results of Levene's tests, either the least significant difference or Tamhane's T2 methods were used in post hoc comparisons for equal or unequal variances respectively.

\section{RESULTS}

For convenience, eight studied chemical elements were divided into two equal groups. Four elements, $\mathrm{Cu}, \mathrm{Zn}, \mathrm{Mn}$ and $\mathrm{Fe}$, participate in biochemical processes and are known as essential elements in plants. ${ }^{9}$ Other elements, $\mathrm{Pb}, \mathrm{Cd}, \mathrm{Co}$ and $\mathrm{Cr}$, were reckoned among toxic metals. Modern pharmacopoeias attribute $\mathrm{Cd}$ and $\mathrm{Pb}$ to Class 1 , Co to Class 2A, and $\mathrm{Cr}$ to Class $3 .{ }^{11}$

The mean concentrations $C_{m}(\exp )$ for essential and toxic elements are shown in Figure $1 \mathrm{a}$ and Figure $1 \mathrm{~b}$ respectively. The studied plants are arranged in order of increasing or falling concentration of a element. In going from nettle through chamomile to SJW (Figure 1a), the $C_{m}(\exp )$ value decreases from 90 to $40 \mu \mathrm{g} / \mathrm{g}$ for $\mathrm{Fe}$, and it simultaneously increases from 5 to $27 \mu \mathrm{g} / \mathrm{g}$ for $\mathrm{Zn}$ and from 45 to $100 \mu \mathrm{g} / \mathrm{g}$ for Mn. The $\mathrm{Cu}$ concentration is rather stable and almost independent of the plant type, fluctuating between 6 and $8 \mu \mathrm{g} / \mathrm{g}$. Toxic metals are detected in a

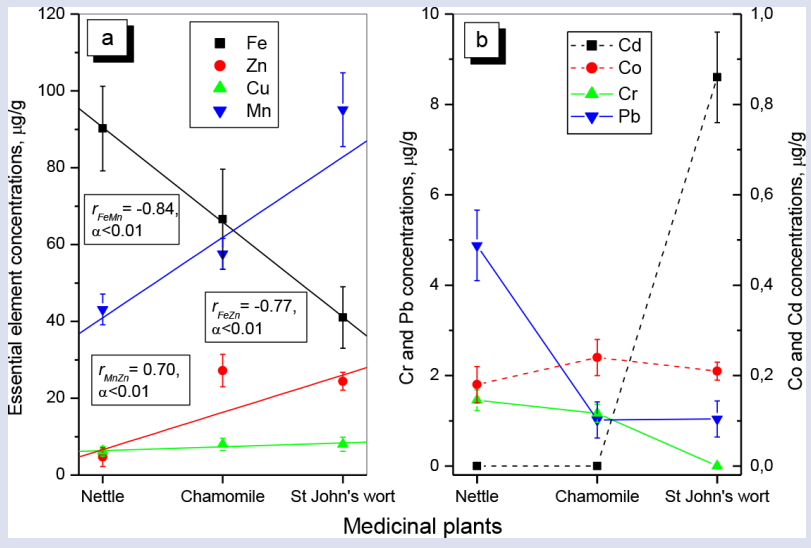

Figure 1: Mean concentrations of essential (a) and toxic (b) metals in studied plants.

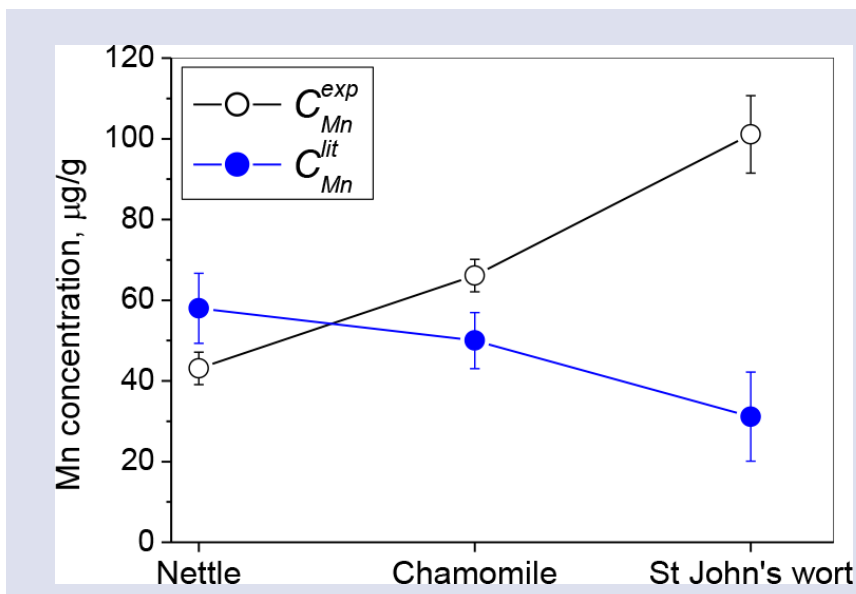

Figure 2: Concentrations of $\mathrm{Mn}$ in various samples of studied plants by the literature (shaded dots) and experimental data (open dots) respectively.

limited number of samples (Figure $1 \mathrm{~b}$ ). For example, $\mathrm{Cr}$ is observed in nettle and chamomile but is below the detection limit in all SJW samples. Cadmium is detected in samples of SJW only. All studied samples contain $\mathrm{Co}$ and $\mathrm{Pb}$.

The results obtained demonstrate the presence of statistically significant pair correlations in elemental concentrations between plants. The significant values of Pearson coefficients rij were found only for three pairs of essential elements labelled in Figure 1a. Iron demonstrates very high anti-correlations with $\mathrm{Mn}$ and $\mathrm{Zn}$ while $\mathrm{Mn}$ also correlates with $\mathrm{Zn}$. No significant correlations were revealed between toxic-toxic or toxicessential pairs.

The average microelement concentrations in different plants were compared between each other to find significant differences between the compared plants. Running an ANOVA test at first, we have got significant results for $\mathrm{Fe}, \mathrm{Mn}, \mathrm{Zn}, \mathrm{Cd}$, and Cr. For these elements, therefore, at least one of the groups tested differs from the other groups. Then the procedure of post hoc multiple comparisons was applied to know which group differentiates. The results for $\mathrm{Fe}, \mathrm{Mn}, \mathrm{Zn}, \mathrm{Cd}, \mathrm{Pb}$ and $\mathrm{Cr}$ are shown in Table 1. The significant differences in $\mathrm{Mn}$ and Fe are detected for all three plant pairs. The Zn concentrations are similar in SJW and chamo- 
Table 1: ANOVA post hoc multiple comparisons of elemental concentrations.

\begin{tabular}{cccccc}
\hline Variables & Plant 1 & Plant 2 & Mean difference & Standard error & a \\
\hline \multirow{2}{*}{ Fe } & SJW & Nettle & $-50.446^{*}$ & 8.049 & 0.000 \\
& SJW & Chamomile & $-26.792^{*}$ & 8.049 & 0.006 \\
$\mathrm{Mn}$ & Nettle & Chamomile & $23.654^{*}$ & 9.858 & 0.034 \\
& SJW & Nettle & $57.926^{*}$ & 10.289 & 0.001 \\
& SJW & Chamomile & $34.928^{*}$ & 10.498 & 0.027 \\
Zn & Nettle & Chamomile & $-22.997^{*}$ & 2.803 & 0.010 \\
& SJW & Nettle & $20.322^{*}$ & 3.502 & 0.000 \\
& SJW & Chamomile & -2.198 & 3.502 & 0.542 \\
$\mathrm{Cd}$ & Nettle & Chamomile & $-22.520^{*}$ & 4.289 & 0.000 \\
& SJW & Nettle & $0.859^{*}$ & 0.017 & 0.001 \\
& SJW & Chamomile & $0.859^{*}$ & 0.017 & 0.001 \\
& Nettle & Chamomile & 0 & 0 & 0.084 \\
$\mathrm{~Pb}$ & SJW & Nettle & -4.483 & 0.781 & 0.157 \\
& SJW & Chamomile & -0.300 & 0.093 & 0.092 \\
& Nettle & Chamomile & 4.183 & 0.785 & 0.070 \\
& SJW & Nettle & -1.456 & 0.229 & 0.050 \\
& SJW & Chamomile & $-1.165^{*}$ & 0.153 & 0.735 \\
\hline
\end{tabular}

* Differences are significant at the 0.05 level (2-tailed)

mile, but they both are significantly higher than in nettle. No concentration difference is observed between plants with detectable levels of $\mathrm{Pb}, \mathrm{Cd}$ and $\mathrm{Cr}$.

\section{DISCUSSION}

There are known many published works which are devoted to the study of elemental composition of nettle, ${ }^{12-18}$ chamomile. ${ }^{12-24}$ and SJW. ${ }^{13,15,16,25-29}$ For brevity, all above-cited 18 papers are hereinafter referred to as the literature data. Their results were averaged to either $C_{m}($ lit $)$ or $C_{\text {med }}$ (lit) and compared with $C_{m}(\exp )$.

The $C_{m}$ (lit) values for $\mathrm{Zn}$ and $\mathrm{Cu}$ in all plants are similar in magnitude to the $C_{m}(\exp )$ values. The $C_{m}(\exp )$ values for $\mathrm{Cu}$ vary from 6 to $8 \mu \mathrm{g} / \mathrm{g}$ (Figure 1a) while the $\mathrm{Cu}$ concentrations derived from the literature range from 2 to $25 \mu \mathrm{g} / \mathrm{g}$ with the mean values 7, 9 and $12 \mu \mathrm{g} / \mathrm{g}$ for nettle, chamomile and SJW respectively. Two samples with anomalously high $\mathrm{Cu}$ content $(83$ и $120 \mu \mathrm{g} / \mathrm{g})$ were reported in. ${ }^{29}$ The minimal $C_{m}(\exp )$ of $\mathrm{Zn}(4.6 \mu \mathrm{g} / \mathrm{g})$ was measured in nettle while the $C_{m}(\exp )$ values were 27 and $25 \mu \mathrm{g} / \mathrm{g}$ for chamomile and SJW respectively (Figure 1a). The calculated $C_{m}$ (lit) values are approximately 34,55 and $46 \mu \mathrm{g} / \mathrm{g}$ for nettle, chamomile and SJW respectively. A spread between individual data is not large except for anomalously high $(>100 \mu \mathrm{g} / \mathrm{g}) \mathrm{Zn}$ content observed in some samples of chamomile. ${ }^{13,19}$ and SJW. ${ }^{13,15,28}$

The mean $\mathrm{Fe}$ concentrations derived from the literature are much higher than the experimental averages: $C_{m}(l i t)$ varies between 180 and $300 \mu \mathrm{g} / \mathrm{g}$ while $C_{m}(\exp )$ changes from 40 to $90 \mu \mathrm{g} / \mathrm{g}$. However, for $\mathrm{Fe}$, both $C_{m}($ lit $)$ and $C_{m}(\exp )$ decrease from nettle to $\mathrm{St}$ John's wort. A rather high scatter of individual results follows from the literature: in all plants differences between minimal and maximal Fe concentrations are of two orders of magnitude. For example, the minimal and maximal Fe concentrations amount to $14-22 \mu \mathrm{g} / \mathrm{g} \cdot{ }^{16}$ and $3456 \mu \mathrm{g} / \mathrm{g} .{ }^{18}$ in nettle, $15-16 \mu \mathrm{g} / \mathrm{g} .{ }^{16}$ and $3125 \mu \mathrm{g} / \mathrm{g} .{ }^{21}$ in chamomile, and 7-9 $\mu \mathrm{g} / \mathrm{g} .{ }^{27}$ and $1177 \mu \mathrm{g} / \mathrm{g} .{ }^{18}$ in SJW respectively. Evidently, the presence of highly contaminated samples elevates $C_{m}$ (lit) while no abnormal amount of Fe was detected in our experiments.
An apparent discrepancy between experimental and literature data is observed for Mn (Figure 2). The $C_{m}$ (lit) value for $\mathrm{Mn}$ decreases from nettle to SJW while $C_{m}(\exp )$ demonstrates an opposite tendency. The minimal Mn concentrations reported in the literature is practically independent of plant type fluctuating between 7 and $8 \mu \mathrm{g} / \mathrm{g} .{ }^{16,25}$ The maximal reported values are $150 \mu \mathrm{g} / \mathrm{g},{ }^{21} 200 \mu \mathrm{g} / \mathrm{g} .{ }^{18}$ and $240-260 \mu \mathrm{g} / \mathrm{g} .{ }^{29}$ for nettle, chamomile and SJW respectively. Despite the presence of samples with higher Mn contents in SJW compared to other plants, the average $C_{m}$ (lit) $(72 \mu \mathrm{g} / \mathrm{g})$ is lower than the average $C_{m}(\exp )$ value $(101 \mu \mathrm{g} / \mathrm{g})$. In turn, the difference between $C_{m}(\exp )$ and $C_{m}$ (lit) is rather small for nettle and chamomile. Therefore, the studied samples of SJW seem to be contaminated with $\mathrm{Mn}$ above the average level.

The concentration distributions of toxic metals by the literature data are characterised by significant non-zero (positive) skewness and kurtosis and do not obey the normal law. To describe the probability of asymmetric datasets, we used medians $C_{\text {med }}($ lit $)$, quartiles $\left(\mathrm{Q}_{25}, \mathrm{Q}_{50}\right.$ and $\left.\mathrm{Q}_{75}\right)$ and concentration minimum $C_{\text {min }}$ (lit) and maximum $C_{\max }$ (lit) (Table 2).

For all three toxic metals in chamomile (Cd was not detected), the $C_{m}(\exp )$ values (Figure $\left.1 \mathrm{~b}\right)$ are rather close to $C_{\text {med }}($ lit) (Table 2) and located within $\mathrm{Q}_{25}$ or $\mathrm{Q}_{50}$ of the published distributions. In other words, the studied chamomile samples are among half samples with the lowest concentrations. The measured concentrations of $\mathrm{Co}$ and $\mathrm{Pb}$ in SJW and $\mathrm{Co}$ and $\mathrm{Cr}$ in nettle demonstrate similar behaviour: the $C_{m}(\exp )$ values (Figure 1b) are lower than $C_{\text {med }}$ (lit) (comparable for $\mathrm{Cr}$ in nettle) and located within $\mathrm{Q}_{25}\left(\mathrm{Q}_{50}\right.$ for $\mathrm{Cr}$ in nettle) of the published datasets. Therefore, the measured concentrations of these elements are among the lowest values observed in the literature (Table 2).

The experimental concentrations of $\mathrm{Pb}$ in nettle are higher than the median value $(1.59 \mu \mathrm{g} / \mathrm{g})$ of published data: the measured $C_{m}(\exp )$ $(4.9 \mu \mathrm{g} / \mathrm{g})$ is comparable with the highest $\mathrm{Pb}$ concentration $(4.8 \mu \mathrm{g} / \mathrm{g})$ detected in nettle. ${ }^{12}$

Since SJW is known as an accumulator of Cd, the highest concentrations of Cd $(\sim 20 \mu \mathrm{g} / \mathrm{g})$ published by ${ }^{29}$ are still much larger than the measured $C_{m}(\exp )(0.86 \mu \mathrm{g} / \mathrm{g})$. 
Table 2: Descriptive statistics for toxic metals in plants by the literature data in comparison with $C_{m}(\exp ) \pm \mathrm{SEM}$.

\begin{tabular}{|c|c|c|c|c|c|c|c|c|c|c|c|c|}
\hline \multirow[b]{2}{*}{ Parameter } & \multicolumn{4}{|c|}{ SJW } & \multicolumn{4}{|c|}{ Chamomile } & \multicolumn{4}{|c|}{ Nettle } \\
\hline & $\mathrm{Cd}$ & Co & $\mathrm{Pb}$ & $\mathrm{Cr}$ & $\mathrm{Cd}$ & Co & $\mathrm{Pb}$ & $\mathrm{Cr}$ & $\mathrm{Cd}$ & Co & $\mathrm{Pb}$ & $\mathrm{Cr}$ \\
\hline$C_{m}(\exp )$ & 0.86 & 0.21 & 1.04 & 0.00 & 0.00 & 0.24 & 1.02 & 1.17 & 0.00 & 0.18 & 4.88 & 1.46 \\
\hline SEM & 0.10 & 0.03 & 0.40 & & & 0.04 & 0.40 & 0.20 & & 0.04 & 0.78 & 0.23 \\
\hline$C_{m}(l i t)$ & 0.74 & 0.46 & 1.97 & 1.07 & 0.56 & 0.39 & 0.90 & 2.87 & 0.10 & 0.61 & 2.42 & 2.67 \\
\hline$C_{m e d}(l i t)$ & 0.61 & 0.42 & 1.60 & 0.49 & 0.22 & 0.24 & 0.72 & 1.70 & 0.10 & 0.48 & 1.59 & 1.20 \\
\hline$C_{\min }($ lit $)$ & 0.05 & 0.03 & 0.01 & 0.04 & 0.09 & 0.01 & 0.06 & 0.07 & 0.06 & 0.08 & 0.88 & 0.66 \\
\hline$C_{\max }($ lit $)$ & 13.00 & 2.60 & 9.00 & 5.00 & 1.70 & 1.40 & 2.73 & 11.19 & 0.14 & 2.35 & 4.80 & 8.71 \\
\hline Skewness & 7.15 & 3.92 & 2.30 & 1.47 & 1.50 & 2.16 & 1.53 & 1.95 & 1.29 & 2.38 & 1.51 & 2.16 \\
\hline Kurtosis & 54.78 & 20.95 & 5.73 & 1.98 & 1.36 & 5.10 & 2.51 & 4.44 & & 5.95 & & 4.72 \\
\hline Quartile $Q_{25}$ & 0.11 & 0.31 & 0.62 & 0.27 & 0.20 & 0.15 & 0.28 & 0.43 & 0.08 & 0.18 & 1.24 & 1.00 \\
\hline Quartile $\mathrm{Q}_{50}$ & 0.61 & 0.42 & 1.60 & 0.49 & 0.22 & 0.24 & 0.72 & 1.70 & 0.10 & 0.48 & 1.59 & 1.20 \\
\hline Quartile $\mathrm{Q}_{75}$ & 0.80 & 0.51 & 2.38 & 1.70 & 0.75 & 0.38 & 1.13 & 3.50 & 0.12 & 0.49 & 3.20 & 1.77 \\
\hline
\end{tabular}

Table 3: LOC and ULSC ranges ${ }^{30-35}$ in comparison with $C_{m}$ (exp) and safe daily intakes.

\begin{tabular}{cccccc}
\hline & LOC, $\mathrm{mg}$ & ULSC, $\mathrm{mg}$ & $\begin{array}{c}\text { Range of } \boldsymbol{C}_{m} \text { (exp), } \\
\mathrm{mg} / \mathbf{k g}\end{array}$ & Most contaminated plant & Safe intake, $\mathbf{g} /$ day \\
\hline $\mathrm{Cu}$ & $0,6-10$ & $10-12$ & $5-12$ & SJW & 1000 \\
$\mathrm{Fe}$ & $8-40$ & 45 & $26-100$ & Nettle & 440 \\
$\mathrm{Mn}$ & $0,3-8$ & 11 & $40-138$ & Nettle & 80 \\
$\mathrm{Zn}$ & $8-18$ & $40-50$ & $2-34$ & Chamomile & 1500 \\
$\mathrm{Co}$ & $0.02-0.04$ & 0,6 & $0.2-0.4$ & SJW & 1500 \\
$\mathrm{Cr}$ & $0.025-0.035$ & 1 & $0.9-1.8$ & Nettle & 560 \\
$\mathrm{Cd}$ & & 0.006 & SJW & 22 \\
$\mathrm{~Pb}$ & & 0.012 & $1.0-6.2$ & Nettle & 16 \\
\hline
\end{tabular}

Since $\mathrm{Pb}$ and $\mathrm{Cd}$ are not involved in the metabolic activity, the presence of these elements can be considered as an indication of the environmental contamination of a plant.

Although an active pharmaceutical ingredient in medicinal plants is mainly associated with organic compounds, microelements can give an additional effect. Many organisations in the world, involved in the study of the influence of various elements on human health, specify recommendations and restrictions on their daily consumption. Two aggregated characteristic exposures, entitled Level of Optimal Consumption (LOC) and Upper Limit of Safe Consumption (ULSC), are constructed on the basis of the universally recognised norms..$^{30-32,34,35}$ The LOC, ULSC and measured $C_{m}(\exp )$ are shown in Table 3 . The ratios of ULSC to the maximal measured concentrations estimate safe limits of daily intakes of the most contaminated herbs from the viewpoint of possible side effect of the microelements (Table 3). The most severe situation concerns possible abuse of $\mathrm{Pb}$ and $\mathrm{Cd}$. For some most contaminated samples, oral daily intake of $22 \mathrm{~g} \mathrm{SJW}$ or $16 \mathrm{~g}$ nettle is equivalent to the ULSC for Cd or $\mathrm{Pb}$ respectively. The measured concentrations of $\mathrm{Pb}$ and $\mathrm{Cd}$ may become restrictive factors for a more intensive safe consumption of the most contaminated samples of nettle and SJW.

\section{CONCLUSION}

The concentrations of essential elements $\mathrm{Fe}, \mathrm{Cu}, \mathrm{Mn}$ and $\mathrm{Zn}$ and toxic metals $\mathrm{Pb}, \mathrm{Cd}$, Co and $\mathrm{Cr}$ were studied by FAAS in samples of herbal medicines nettle, chamomile and SJW grown in Ukraine. The Cu content varies between 5.7 and $9.6 \mu \mathrm{g} / \mathrm{g}$ and is weakly dependent on the plant type. The Fe concentration decreases from 90 to $40 \mu \mathrm{g} / \mathrm{g}$ while $\mathrm{Zn}$ and Mn increase from 5 to $27 \mu \mathrm{g} / \mathrm{g}$ and 45 to $100 \mu \mathrm{g} / \mathrm{g}$, respectively, in going from nettle through chamomile to SJW. Statistically significant negative correlations in $\mathrm{Fe}-\mathrm{Mn}$ and $\mathrm{Fe}-\mathrm{Zn}$ pairs, as well as a positive $\mathrm{Zn}-\mathrm{Mn}$ relationship, follow from the results obtained.

The $\mathrm{Cr}$ concentrations are below the detection limits in all studied samples. Cobalt was detected in all plants, and its levels $(0.2-0.25 \mu \mathrm{g} / \mathrm{g})$ are comparable with those published in the literature. Lead is detected in all plants; its highest-level amounts to $4.9 \mu \mathrm{g} / \mathrm{g}$ in nettle and is an order of magnitude lower in other plants. Cadmium $(\sim 0.85 \mu \mathrm{g} / \mathrm{g})$ is detected in some samples of SJW while this element is below the detection limit in other plants. The measured levels of both $\mathrm{Pb}$ and $\mathrm{Cd}$ still secure against overuse of toxic metals with herbal remedies. However, the limits of tolerable daily intakes are not so far from the doses which can be accumulated during very intensive consumption of the considered remedies.

\section{ACKNOWLEDGEMENT}

The authors would like to thank the Faculty of Chemical and Biopharmaceutical Technologies of Kyiv National University of Technologies and Design for the research facilities provided.

\section{CONFLICT OF INTEREST}

The authors declare that there is no conflict of interest.

\section{ABBREVIATIONS USED}

SJW: St John's wort; ANOVA: one-way analysis of variance; FAAS: flame atomic absorption spectroscopy; LOC: level of optimal consumption; ULSC: upper limit of safe consumption.

\section{REFERENCES}

1. Lynch N, Berry D. Differences in perceived risks and benefits of herbal, over- 
the-counter conventional, and prescribed conventional, medicines, and the implications of this for the safe and effective use of herbal products. Compl. Therapies in Med. 2007;15(2):84-91.

2. Kristanc L, Kreft S. European medicinal and edible plants associated with subacute and chronic toxicity part II: Plants with hepato-, neuro-, nephro- and immunotoxic effects. Food Chem. Toxicol. 2016;92(6):150-64.

3. Kristanc L, Kreft S. European medicinal and edible plants associated with subacute and chronic toxicity part I: Plants with carcinogenic, teratogenic and endocrine-disrupting effects. Food Chem. Toxicol. 2016;92(6):150-64.

4. Chizzola R. Metallic mineral elements and heavy metals in medicinal plants. Med. Aromat. Plant Sci. Biotechnol. 2012;6:39-53.

5. Pohl P, Dzimitrowicz A, Jedryczko D, Szymczycha-Madeja A, Welna $M$, Jamroz P. The determination of elements in herbal teas and medicinal plant formulations and their tisanes. J. Pharm. Biomed. Anal. 2016;130:326-35.

6. Locatelli C, Melucci D, Locatelli M. Toxic metals in herbal medicines. A review. Curr. Bioact. Compd., 2014;10:181-8.

7. Gil F, Hernández AF, Martín-Domingo MC. Toxic Contamination of Nutraceuticals and Food Ingredients. In: Gupta RC, ed. Nutraceuticals: Efficacy, Safety and Toxicity. Amsterdam: Elsevier Inc. 2016;825-37.

8. Zhang J, Wider B, Shang H, Li X, Ernst E. Quality of herbal medicines: Challenges and solutions. Complem. Therapies in Med. 2012;20(1):100-6.

9. Kabata-Pendias A. Trace Elements in Soils and Plants (4 ${ }^{\text {th }}$ Ed.). CRC Press, Boca Raton, USA. 2010

10. Goldhaber SB. Trace element risk assessment: essentiality vs Toxicity. Regulatory Toxic. Pharm. 2003;38(2):232-42

11. Q3D Elemental Impurities. Guidance for Industry. 2015.USA: ICH.

12. Basgel S, Erdemoglu SB. Determination of mineral and trace elements in some medicinal herbs and their infusions consumed in Turkey. Sci. Total Envir. 2006:359(1):82-9.

13. Igamberdieva PK, Usmanov RD, Danilova EA. Investigation of macro- and trace chemical element content of medicinal plants of southern Fergana and prospects of their application in the treatment of diseases. Trace Element in Med. 2016;17(3):48-53.

14. Kara D. Evaluation of trace metal concentrations in some herbs and herbal teas by principal component analysis. Food Chem. 2009;114(1):347-54.

15. Mihaljev Z, Zivkov-Balos M, Cupic Z, Jaksic S. Levels of some microelements and essential heavy metals in herbal teas in Serbia. Acta Pol. Pharm. 2014;71(3):385-91

16. Pytlakowska K, Kita A, Janoska P, Polowniak M, Kozik V. Multi-element analysis of mineral and trace elements in medicinal herbs and their infusions. Food Chem. 2012;135(2):494-501

17. Ozcan MM, Akbulut M. Estimation of minerals, nitrate and nitrite contents of medicinal and aromatic plants used as spices, condiments and herbal tea. Food Chem. 2007:106(2):852-8

18. Tokalioglu S. Determination of trace elements in commonly consumed medicina herbs by ICP-MS and multivariate analysis. Food Chem. 2012;134(4):2504-8.

19. Abou-Arab AAK, Soliman Kawther M, El Tantawy ME, Ismail Badeaa R, Khayria N. Quantity estimation of some contaminants in commonly used medicinal plants in the Egyptian market. Food Chem. 1999;67(4):357-63.

20. Arpadjan S, Celik, Taskesen S, Gucer S. Arsenic, cadmium and lead in medicinal herbs and their fractionation. Food Chem. Toxicol. 2008;46(8):2871-5.

21. De La Calle I, Costas M, Cabaleiro N, Lavilla I, Bendicho C. Fast method for multielemental analysis of plants and discrimination according to the anatomical part by total reflection X-ray fluorescence spectrometry. Food Chem. 2013;138(1):234-41.

22. Malik J, Frankova A, Drabek O, Szakova J, Ash C, Kokoska L. Aluminium and other elements in selected herbal tea plant species and their infusions. Food Chem. 2013;139(1):728-34.

23. Ozcan MM, Unver A, Ucar T, Arslan D. Mineral content of some herbs and herbal teas by infusion and decoction. Food Chem. 2008;106(3):1120-7.

24. Stanojkovic-Sebic A, Maksimovic S, Pivic R, Dinic Zoran Z, Maksimovic J. Evaluation of heavy metals content in selected medicinal plants commonly used as components for herbal formulations. In: Proc. 7th CMAPSEEC.2015;21(3):317-25.

25. Bu K, Cizdziel JV, Reidy L. Analysis of herbal supplements for selected dietary minerals and trace elements by laser ablation- and solution-based ICPMS Microchem. J. 2013:106:244-9.

26. Filipiak-Szok A, Kurzawa M, Szlyk E. Determination of toxic metals by ICP-MS in Asiatic and European medicinal plants and dietary supplements. J. Trace Elem. Med. Biol. 2015;30:54-8

27. Gomez MR, Cerutti S, Sombra LL, Silva MF, Martınez LD. Determination of heavy metals for the quality control in Argentinian herbal medicines by ETAAS and ICP-OES. Food Chem. Toxicol. 2007;45(6):1060-4.

28. Kalny P, Fijatek Z, Daszczuk A, Ostapczuk P. Determination of selected microelements in polish herbs and their infusions. Sci. Total Envir. 2007;381(1):99-104.

29. Owen JD. Investigation of the elemental profiles of Hypericum perforatum as used in herbal remedies. Submitted to the University of Hertfordshire for PhD degree. Hertfordshire University: UK. 1-226.

30. AHPA. Heavy Metals: Analysis and Limits in Herbal Dietary Supplements. USA 2009

31. Commission Regulation (EC) No 1881/2006 of 19 December 2006 setting maximum levels for certain contaminants in foodstuffs. Official J. EU. 20.12.2006. L364/5-L364/34. Available from: http://data.europa.eu/eli/reg/2006/1881/201604-01.

32. Guideline on the specification limits for residues of metal catalysts or metal reagents. European Medicin. Agency, Doc. Ref. EMEA/CHMP/SWP/4446/2000. EMA, London. 2008.

33. Standard NSF/ANSI 173-2016. Dietary supplements. USA. 2016

34. US Pharmacopeia, <232> Elemental Impurities - Limits. The US Pharmacopeia Convention. Edition. 2013;151-3.

35. WHO guidelines for assessing quality of herbal medicines with reference to contaminants and residues. WHO Press, Geneva. 2007.

\section{GRAPHICAL ABSTRACT}

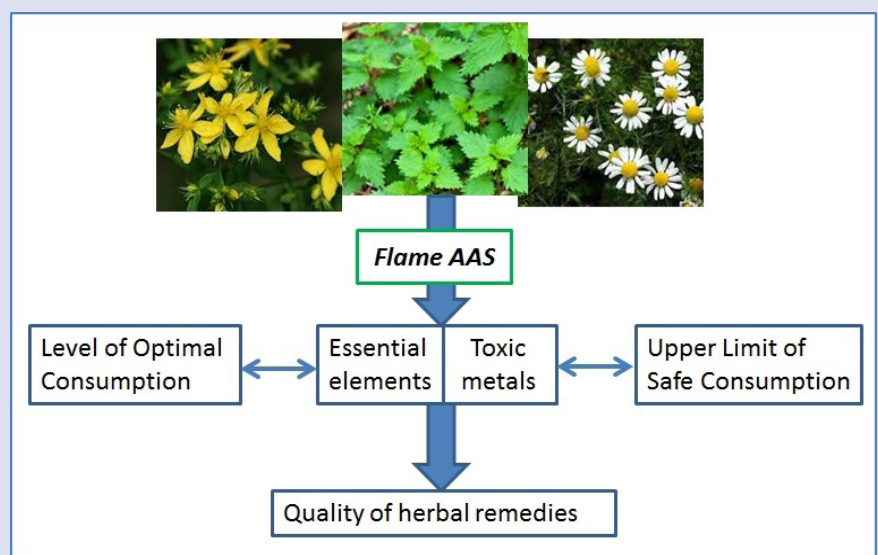

\section{SUMMARY}

- Statistically significant correlations were found between element concentrations. They are negative for Fe-Mn and Fe-Zn pairs and positive for $\mathrm{Zn}-\mathrm{Mn}$.

- The studied samples of St John's wort are more contaminated with $\mathrm{Cd}$ (up to $0.85 \mu \mathrm{g} / \mathrm{g})$ than other plants, while the highest $\mathrm{Pb}$ content $(4.9 \mu \mathrm{g} / \mathrm{g})$ is observed in some samples of nettle

- The measured levels of both $\mathrm{Pb}$ and $\mathrm{Cd}$ secure against overuse of toxic metals with herbal remedies. 


\section{ABOUT AUTHORS}

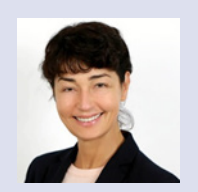

Dr Tetiana Derkach: Chair of Professional Education in Technologies and Design and Professor of the Department of Industrial Pharmacy at Kyiv National University of Technologies and Design, Ukraine. She obtained her $\mathrm{PhD}$ in Chemistry from Dnipro National University in 2000 and Sc.D. in Education (habilitation) from the Institute of Higher Education (Kyiv, Ukraine) in 2015. Her current research interests include the use of information and communication technologies in teaching pharmacy and chemistry, as well as the study of the chemistry of medicinal plants and herbal remedies.

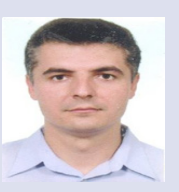

Dr Volodymyr Khomenko: Senior Researcher at the Department of Electrochemical Energetics and Chemistry of Kyiv National University of Technologies and Design. He obtained his doctorate in Engineering from the National University of Technology "Kyiv Polytechnic Institute" in 2001. His current research activity focuses on composite materials for power sources, as well as trace element analysis in pharmaceutical and environmental samples. He published more than 30 journal articles, and his works are cited in 3440 papers. His Hirsch index is $h=16$.

Cite this article: Derkach T, Khomenko V. Elemental Composition of the Medicinal Plants Hypericum perforatum, Urtica dioica and Matricaria chamomilla Grown in Ukraine: A Comparative Study. Pharmacog J. 2018;10(3):486-91. 